\title{
Abstract \\ Oligonucleotide Array for Mutation Analysis in Familial Breast Cancer
}

Andres Metspalu, Krista Kaasik, Neeme Tõnisson and Ants Kurg

Institute of Molecular and Cell Biology, Tartu University, Tartu, Estonia

Detecting recurrent mutations in the BRCA1 and BRCA2 genes presents a challenge because these mutations are scattered throughout each of the genes. An efficient mutation detection system for these genes should have the properties of a scanning methodology in combination with the fidelity of DNA sequence analysis. We have evaluated an Arrayed Primer EXtension (APEX) methodology applied to the identification of mutations in BRCA1 and BRCA2. APEX consists of oligonucleotide primers arrayed in a two dimensional format on a glass surface. A patient DNA sample amplified via PCR is annealed to the primers which promote sites for template-dependent DNA polymerase extension reactions. Four unique fluorescently-labeled dideoxy-nucleotides are the substrates for mutation detection. A CCD camera images the fluorescence of the chip. The BRCA1 gene chip scans for 42 recurrent mutations across six different exons and the BRCA2 chip scans for 11 recurrent mutations in 5 exons. The majority of labor and time required for the use of DNA chips is associated with sample preparation. Furthermore, the chip fidelity and sensitivity are dependent upon the quality and secondary structure of the DNA sample. We have developed a PCR-based sample preparation protocol that can be applied to any DNA target for efficient DNA chip analysis. The time required for entire APEX analysis is less than four hours; and the cost (including sample preparation) is approximately $\$ 5$. The signal to noise ratio of APEX is on the average 10:1 which enables unambiguous heterozygous readout. APEX provides a cost-competitive platform for efficient mutation detection of mutations widely scattered across multiple genes. 


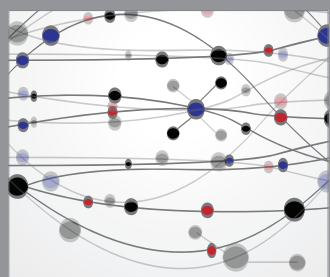

The Scientific World Journal
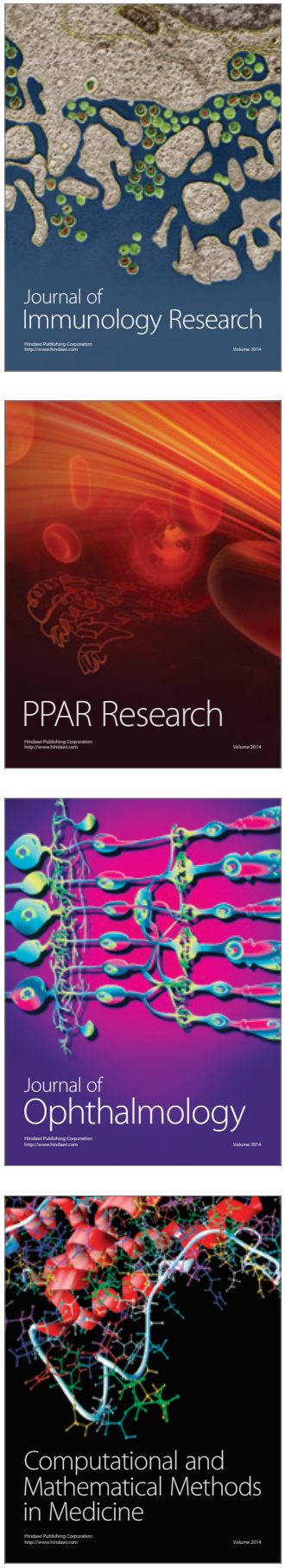

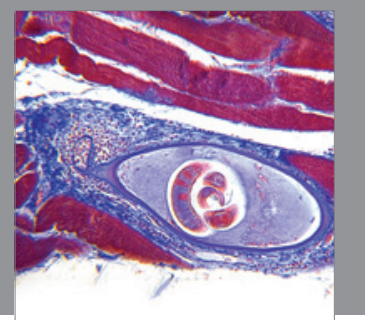

Gastroenterology

Research and Practice
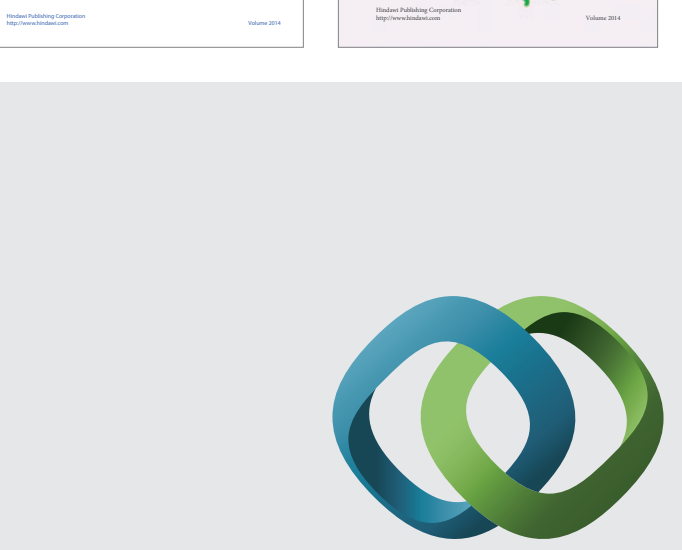

\section{Hindawi}

Submit your manuscripts at

http://www.hindawi.com
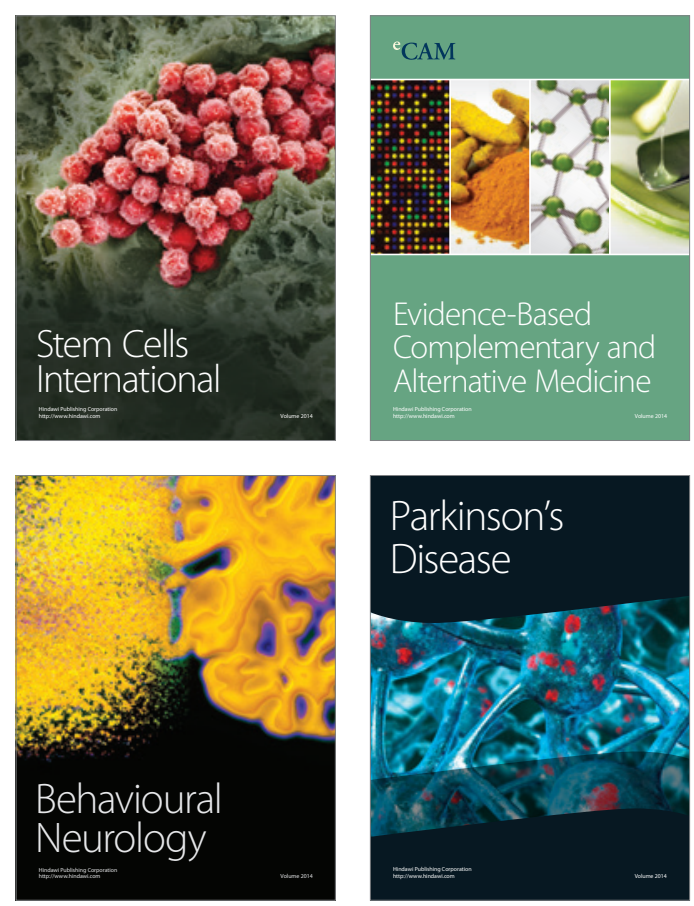

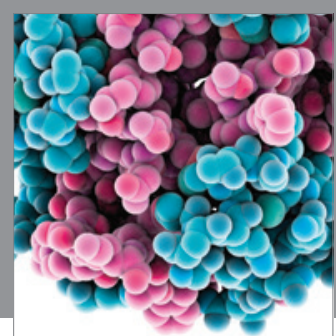

Journal of
Diabetes Research

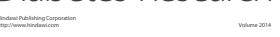

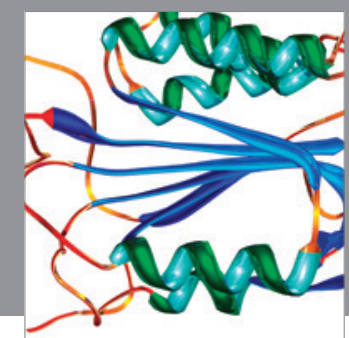

Disease Markers
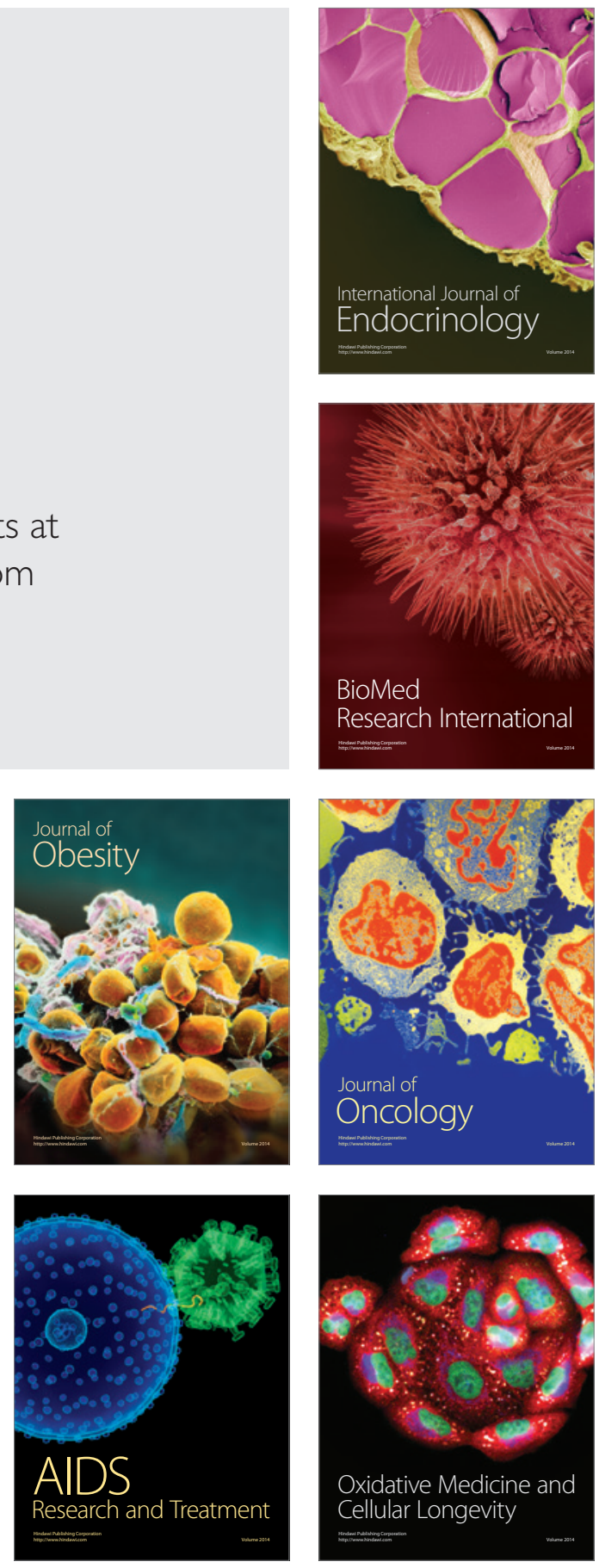